had been made by means of a blood examination. It may be noted that the glandular enlargement progressed rapidly in the last few days of life. 5. Blood examination. This showed conclusively that the case was one of acute lymphatic leukæmia. An interesting point in this connexion is the enormous number of lymphocytes present. 6. Priapism. During the whole of the time that this patient was under observation there was marked and continuous priapism and this condition gave rise to much distress. In conclusion, one may say that a case like this shows the very great clinical importance of a blood examination in doubtful cases and, indeed, in this instance it was thus possible to diagnose the presence of lymphatic leukæmia before any glandular enlargement was observable.

Cardiff.

\section{A CASE OF CONTRACTURE AND ANKY- LOSIS AT THE KNEE TREATED BY STEEL-BAR TRACTION AND HESSING'S SPLINT CASE APPLIANCE.}

BY T. H. OPENSHAW, C.M.G., M.S. DURH., F.R.C.S. ENG.,

SURGEON TO THE LONDON FOSPITAL AND SURGEON TO THE NATIONAL ORTHOPADIC HOSPITAL.

THE patient, a boy, aged 15 years, came under my care at the London Hospital in January, 1904, with close fibrous ankylosis and contracture of the left knee. The knee first became painful and stiff when the patient was five years old. He was treated with plaster of Paris, \&c., but abscesses formed which burst. There were two cicatrices above the

FIG. 1.

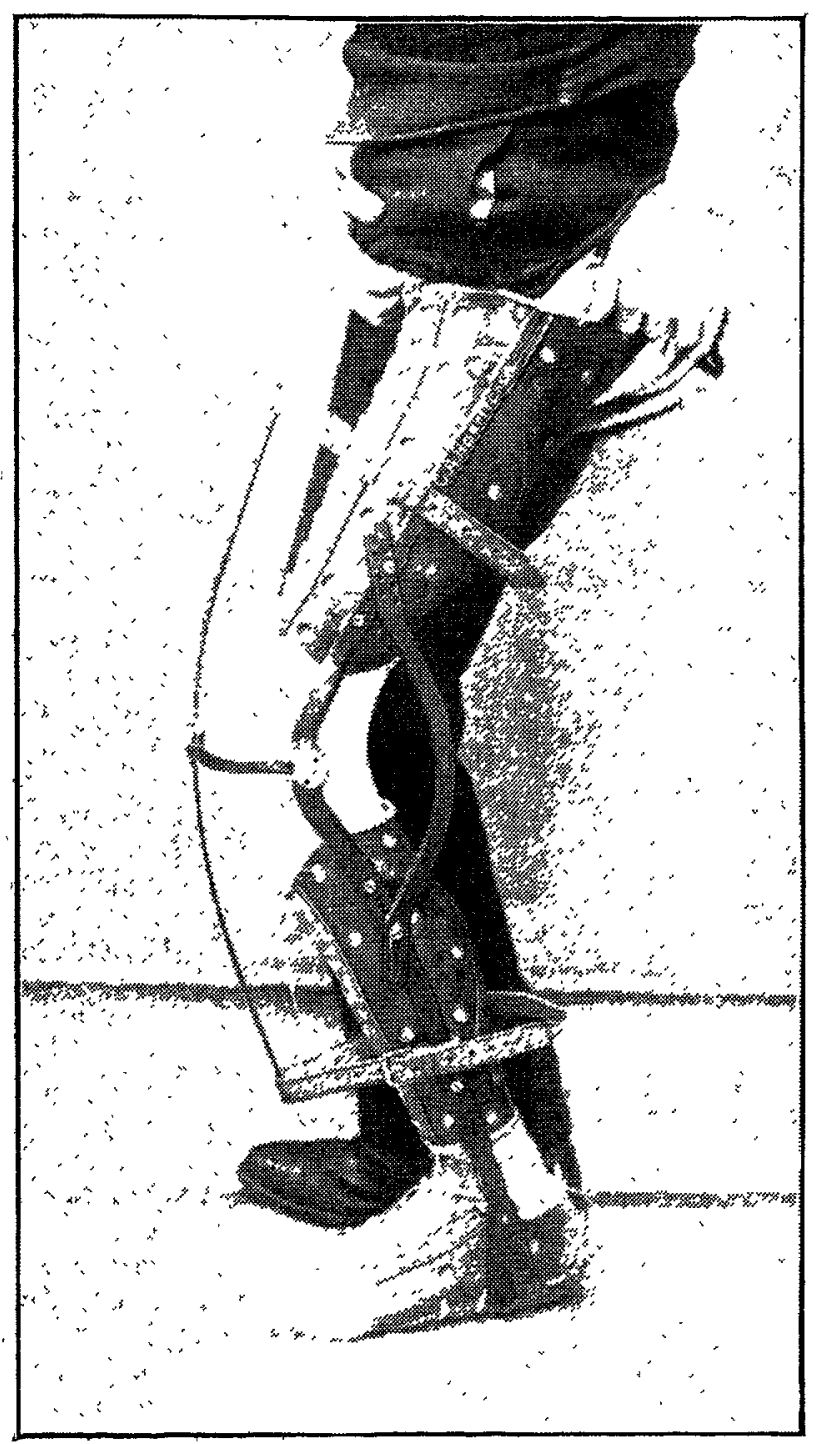

The apparatus applied, Feb. 26th. The knee is flexed at an angle of 112 clegrees. external condyle and one over the ligamentum patellæ and evidences of extensive tuberculous disease resulting in ankylosis. The knee became flexed and contracted and this remained so, but during the year 1903 it had been getting slowly more marked. In January, 1904, the angle of the knee-joint was 112 degrees. The hamstring muscles were contracted. There was power of motion of the knee only to the extent of one degree. The muscles of the thigh were wasted but there was no paralysis. The patient walked well

FIG. 2.

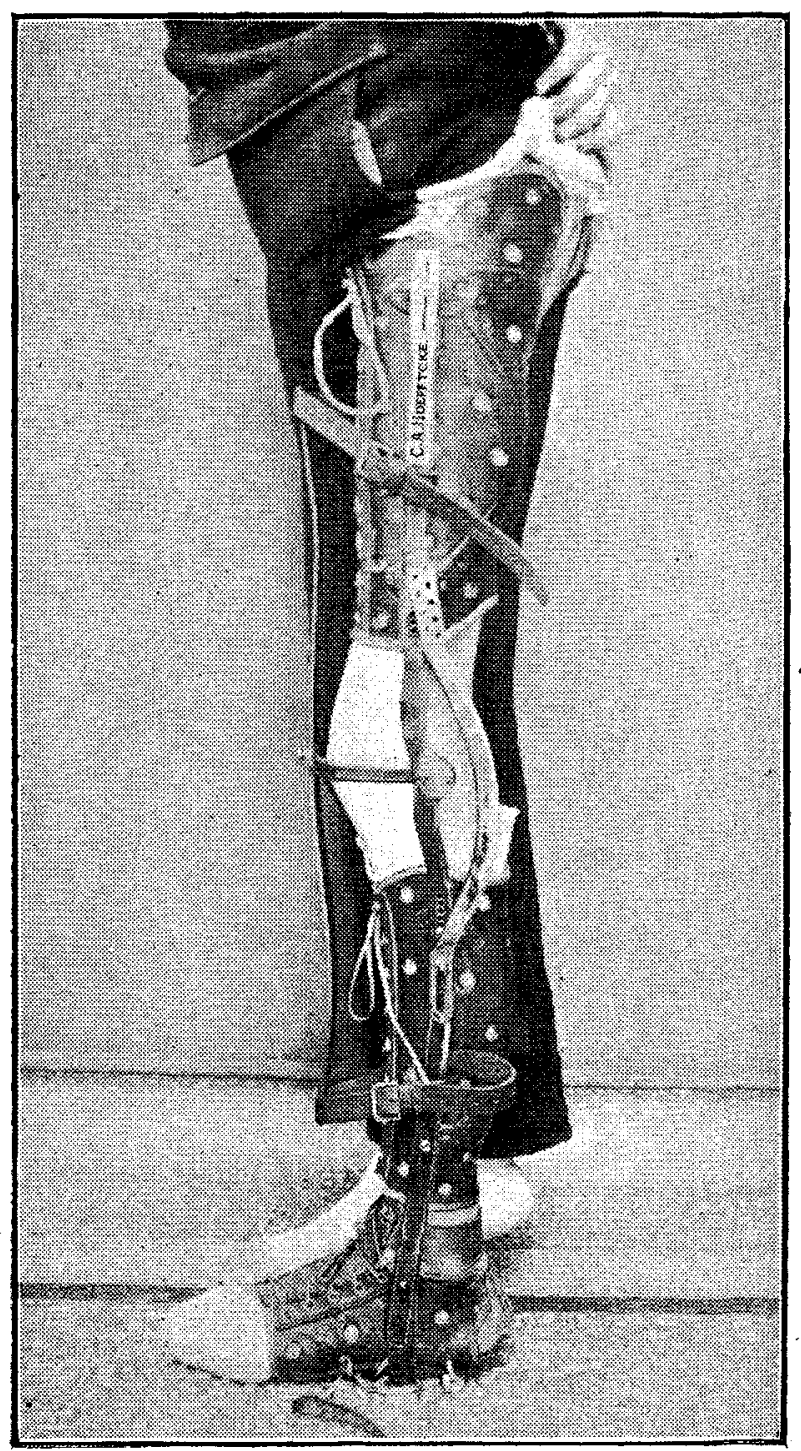

Showing the knee straight on April 15th.

with the toes on the ground but the left half of the pelvis dropped four inches in order that the toes should reach the ground. There was marked left dorso-lumbar lateral curvature.

On Feb. 26th Hessing's splint case appliance, with steelbar traction, was adjusted to the limb, the knee being then flexed at an angle of 112 degrees (see Fig. 1). Very slowly and steadily the knee began to extend, without pain, œdema, or other inflammatory symptom. As the knee extended so the arched steel bar at the back of the knee was readjusted and on April 15th the leg was straight (see Figs. 2 and 3). The accompanying diagram (Fig. 4) shows the steady improvement that had taken place at different dates.

The appliance consists of three cases made of leather, one accurately moulded to the thigh, a second to the calf, and a third to the foot. Each is strengthened with steel bars. These steel bars are accurately moulded to the part and are then sunk into the softened leather. These bars carry certain plates of steel which project through the leather and in which are various screw-holes for their firm attachment to two lateral steel bars which pass down from the thigh case to the ankle. The leather cases by this means not only are firmly attached to the lateral bars but can be adjusted either a little upwards or a little downwards. The splint thus forms one uniform whole which accurately fits 
FIG. 3.

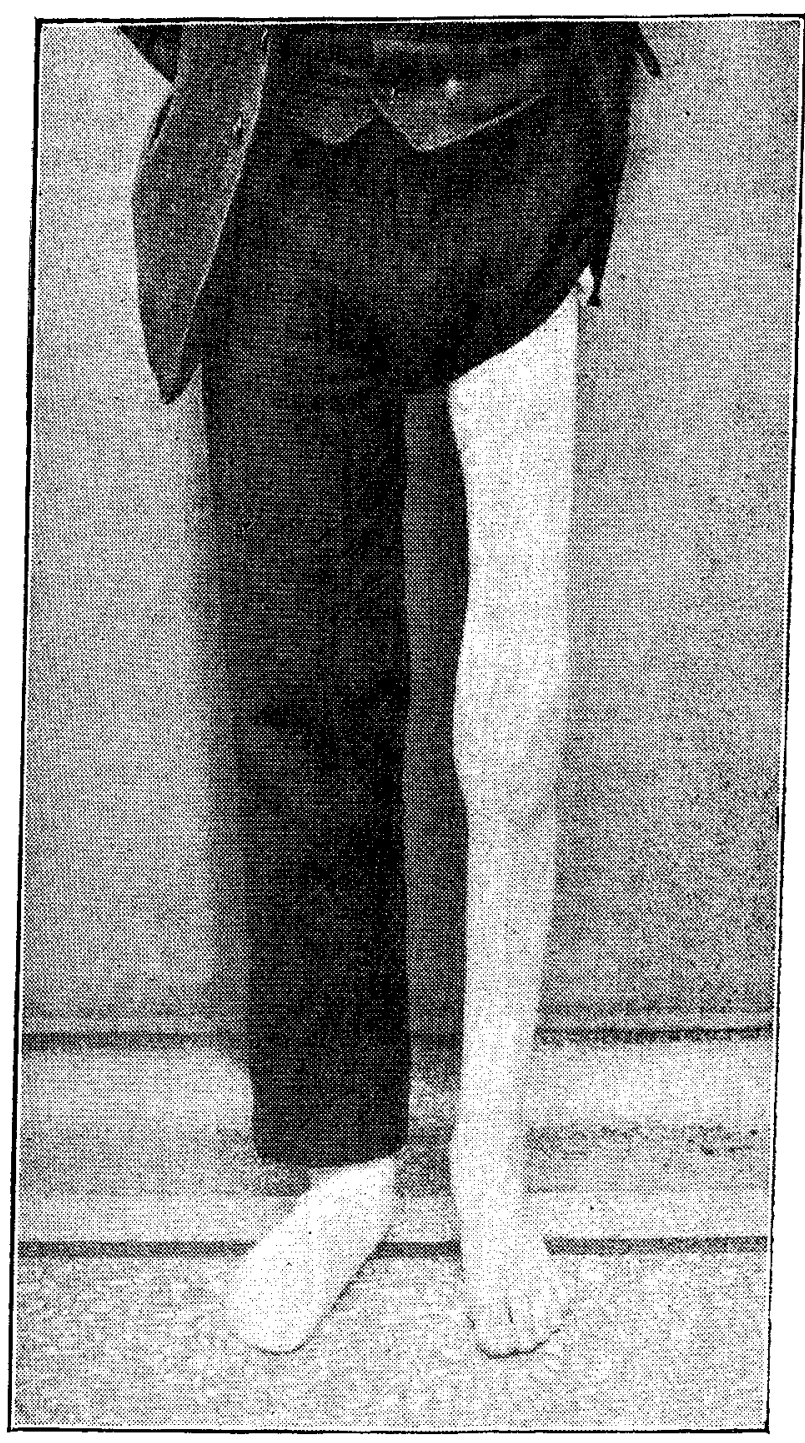

Front view of straight leg, April 15th.

the leg from the ankle-joint to the top of the thigh. Each leather case is open in front and is made to lace up.

The foot leather case is fitted with a sole plate carrying upright bars on each side with steel pegs in them. The pegs fit in holes at the lower end of each of the lateral bars and by this means traction upon the lower part of the leg is

FIG. 4.

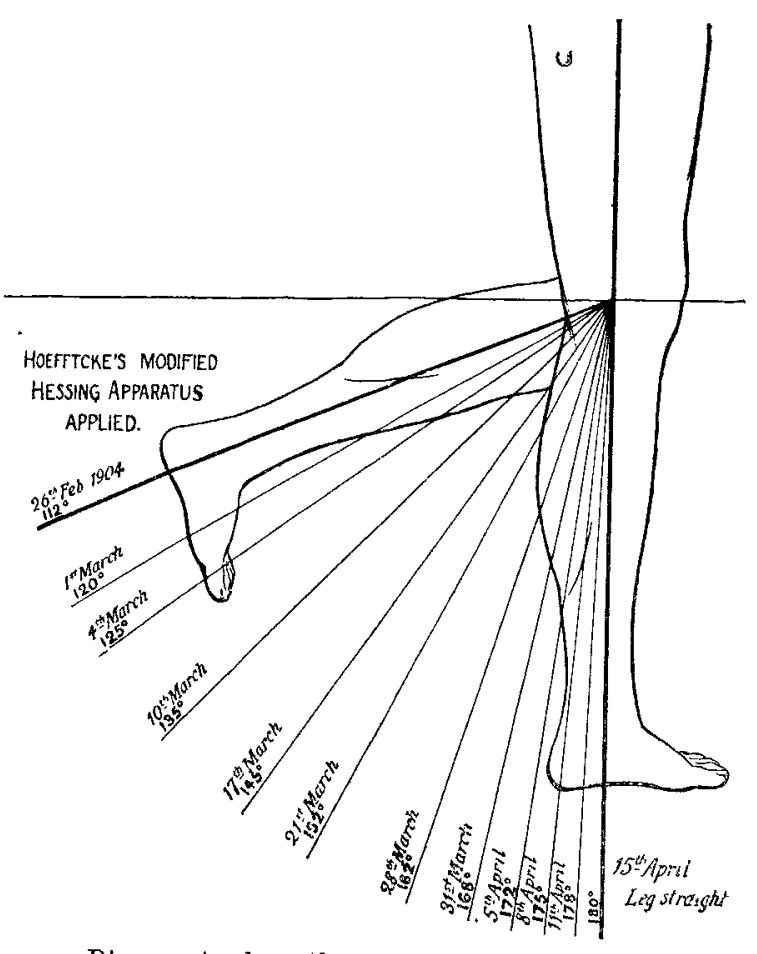

Diagram to show the progress of the case. made. Crossing the front of the knee is a steel arch fitted on each side into the joint between the thigh and the leg. It carries a slot through which passes an elastic steel bar, to each end of which is attached a strap. These straps buckle to the lateral steels of the thigh and leg cases (see Fig. 1). The upper end of the steel bar having been buckled tight, as the lower straps are tightened so the leg is drawn forward and the knee is straightened. At the back of the knee is an arched steel bar, with a slot at the lower end and with screw-holes at the upper end. As the leg gets straighter the straightening is followed up and secured by increasing the length of this bar. The slot at the lower end of the bar allows the knee to extend but prevents flexion.

Remarks. - This case was one of the closest possible fibrous ankylosis, practically no movement being obtainable at the knee-joint. The contracture and flexion of this joint were steadily getting worse, so that only the tips of the toes touched the ground, and the pelvis being tilted scoliosis resulted. The knee was straightened in six weeks without any pain being experienced during the process. The patient was not incapacitated even for a day. The movement at the knee-joint continued very slowly to increase in extent.

In my opinion, every case of fibrous ankylosis and contracture of the knee can be straightened by means of this steel-bar traction method. This method should supersede forcible straightening of the knee under anæsthetics, which occasionally results in rupture of the popliteal vessels or in lighting up the quiescent tuberculous disease and frequently causes an increase of the pre-existing stiffness of the joint.

Wimpole-street, $\mathbf{W}$.

\section{HUMAN PIROPLASMOSIS. ${ }^{1}$}

By C. DONOYAN, M.D. R.U.I.,

MAJOR, I.M.S.; SECOND PHYSICIAN, GENERAL HOSPITAL, MADRAS. (Concluding Part.)

THE piroplasmata are found in the peripheral circulation, the spleen, the liver, the bone marrow, the submucosa of the large intestine, ulcers of the skin and large intestines, and occasionally in the kidneys and the suprarenals.

In the peripheral circulation the parasite is met with in the red blood corpuscles and in the polymorphonvclear and mononuclear leucocytes; it is only when the temperature is high, between $103^{\circ}$ and $104^{\circ} \mathrm{F}$, that their occurrence in this situation is noticed. Their numbers vary and are never at any time great; in an examination of a slide for half an hour six might be found in the red blood corpuscles and double to treble that number in the leucocytes. In the red blood corpuscles the organism is small, $1 \mu$ to $1 \frac{1}{2} \mu$ in diameter, in shape bacillary, pear-shaped, oval or spherical, with one chromatin mass, oval or oblong, always placed at the circumference. The forms represented in Fig. 7 of the coloured plate attached to the first portion of my paper depict their different shapes. The red blood corpuscles containing the one-chromatin parasite are not altered in shape, size, or in staining reaction from the normal uninfected cells. Here also may be found rarely shrunken red cells stained blue instead of greenish-yellow, which contain the double chromatin parasite to be described immediately below. In the polymorphonuclear and mononuclear leucocytes (Fig. 7) the organisms always possess double chromatin masses.

In the blood taken by puncture from the spleen during

1 The second and concluding part of the paper, the first part of which was published in THE LAYCET of Sept. 10th, 1904, p. 744. This part was lost in transit, which accounts for the delay in publication. A detailed description is appended of the coloured illustration which appeared in the first part.

Description of Plate.

(Magnification about 1500 diameters ; Romanowsky staining was used.) FIG. 1.-The different forms of piroplasma Donovani found in blood taken by puncture of spleen during life.

FrG. 2.-Details of structure of parasite showing racuoles and chromatin threads attacher to the smaller chromatin mass.

FIG. 3. - Cleared specimen showing blue protoplasm of the parasite.

FIG. 4.-Changes in the infected red blood corpuscles.

FIG. 5.-Multiplication forms.

FIG. 6.-Parasites associated with pigment in red blood corpuscles and macrophage.

FIG. 7.- Parasites in the peripheral circulation.

FIr. 8. - Macrophage from spleen blood with nimerous piroplasmat in protoplasm, one apparently in the nucleus. Nucleus of splenic cell with dark nodal staining resembling piroplasma Donovani in appearance.

FIG. 9.-Blood taken from a smear post mortem. 